\title{
APOA1/C3/A4 gene cluster variability and lipid levels in Brazilian children
}

\section{E. de França ${ }^{1}$, \\ J.G.B. Alves ${ }^{2}$ and M.H. Hutz ${ }^{1}$}

\section{Correspondence \\ M.H. Hutz \\ Departamento de Genética, UFRGS \\ Caixa Postal 15053 \\ 91501-970 Porto Alegre, RS \\ Brasil \\ Fax: +55-51-3316-7311 \\ E-mail: mara.hutz@ufrgs.br}

Research supported by CNPq, PRONEX and Laboratórios CERPE, Recife, PE, Brasil.

Received April 30, 2004

Accepted January 6, 2005

$\ldots \ldots \ldots \ldots \ldots \ldots \ldots$

\author{
'Departamento de Genética, Universidade Federal do Rio Grande do Sul, \\ Porto Alegre, RS, Brasil \\ ${ }^{2}$ Instituto Materno Infantil de Pernambuco, Escola de Pós-Graduação em Saúde \\ Materno-Infantil, Recife, PE, Brasil
}

\section{Abstract}

Genetic studies have suggested that polymorphisms of genes coding for apolipoproteins are significant determinants of serum lipoprotein and lipid levels in adults. However, only a few studies have investigated the association of these polymorphisms in children. Therefore, in the present investigation we studied the distribution of APOA1 -75 G>A, +83 C>T, APOC3 -482 C>T, -455 T>C and $3238 \mathrm{C}>\mathrm{G}$, and $A P O A 4 \mathrm{Q} 360 \mathrm{H}$ and $\mathrm{T} 347 \mathrm{~S}$ polymorphisms and their influence on plasma lipoprotein levels in children from a Brazilian northeastern admixed population. The seven polymorphic sites were genotyped in 414 children aged 5 to 15 years (mean $8.9 \pm 2.9)$. The genotypes of the seven polymorphic sites were assessed by PCR-RFLP methods. The frequencies of the less common alleles were, in general, intermediate among parental populations, as expected. Strong linkage disequilibrium was detected between polymorphisms at the APOA1, APOC 3 and APOA4 loci in this admixed population sample. Overall the genotype effects seen in adults were weaker or absent in children. The APOC3/-455 and APOA4 T347S variants showed significant effects on HDL cholesterol in girls $(\mathrm{P}=0.033$ and $\mathrm{P}=0.016$, respectively). Significantly higher plasma total $(\mathrm{P}=0.003)$ and LDL cholesterol $(\mathrm{P}=0.004)$ levels were observed in boys who were carriers of the $3238 \mathrm{G}$ allele at the $A P O C 3 / 3238 \mathrm{C}>\mathrm{G}$ site. These results disclosed an overall absence of associations between these polymorphisms and lipids in children. This finding is not unexpected because expression of the effect of these polymorphisms might depend on the interaction with environmental variables both internal and external to the individual.

The genes coding for apolipoproteins AI (apoA-I protein; APOAl gene), C-III (APOC3) and A-IV (APOA4) lie within a 17$\mathrm{kb}$ DNA segment on the long arm of chromosome 11 (1). apoA-I is synthesized primarily in the liver and to a lesser extent in the small intestine. It is the major apolipoprotein component of high-density lipoproteins (HDL)
Key words - Apolipoproteins - Gene variants - Lipid levels - Children . Childien and plays a key role in reverse cholesterol transport from peripheral tissues to the liver. It is also the obligatory activator of lecithincholesterol acyltransferase (2). The liver and intestine also synthesize apoC-III, although the precise function of apoC-III is not fully understood. There is increasing evidence associating this apolipoprotein with the ca- 
tabolism of triglyceride-rich lipoproteins (TGRL). Animal studies have shown that apoC-III acts as an inhibitor of the lipoprotein lipase-mediated hydrolysis of TGRL (3). The precise physiological role of apoA-IV is also not completely understood, but there is evidence suggesting that the primary role of apoA-IV is in intestinal lipid absorption (4). Several functions for apoA-IV have been proposed, including activation of lecithincholesterol acyltransferase, modulation of lipoprotein lipase activity, regulation of cholesterol ester transfer between HDL and LDLs, and facilitation of cholesterol efflux from peripheral cells. More recently, in vivo experiments have provided evidence that this protein may be involved in inhibition of food intake following the ingestion of fat, thus modulating body weight gain (4).

Several polymorphic sites have been identified in the APOA1-C3-A4 gene cluster, and have been associated with lipid levels (5-7), and coronary artery disease (8) with conflicting results (9). Genetic factors are considered to be important determinants of plasma lipoprotein in adults; however, the role of genetics in determining plasma lipoproteins in children and adolescents is not clear. Moreover, except for few sporadic studies, the distribution of apolipoprotein polymorphisms has been mainly studied in European and European-derived populations. It is well known that differences among populations in the relative frequency of susceptibility genotypes or environmental exposure will contribute to differences in the utility of a genotype for predicting a trait within a particular population. Our objective, therefore, was to test for associations between polymorphisms of the APOAl-C3-A4 gene cluster and lipid levels in a sample of Brazilian children of mixed ethnicity free of adult diseases, taking no medications, and socioeconomically homogeneous.

The investigation conformed with the principles outlined in the Declaration of Helsinki and was approved by the Hospital Ethics Committee. Parents provided written informed consent and probands provided verbal consent to participate.

The study population resulted from an intense process of admixture since the XVI century among Europeans, Africans, and Amerindians (10). The sample consisted of 414 healthy children aged 5 to 15 years (mean $8.9 \pm 2.9$ ) selected at a pediatric hospital (Instituto Materno-Infantil de Pernambuco) in Recife, the capital of the Brazilian Northeastern State of Pernambuco. All children as well as their parents were born in the State of Pernambuco. A questionnaire was completed during an interview with the parents, which included details on medical history, drug intake, lifestyle variables such as physical activity, and demographic data. Exclusion criteria were secondary hyperlipidemia due to renal, liver or thyroid disease, diabetes and a parental history of diabetes or coronary artery disease.

The weight and height of subjects were measured in the morning after a 12-h fast. Height was measured to the nearest centimeter using a rigid stadiometer and weight was measured to the nearest $0.1 \mathrm{~kg}$ using a calibrated electronic scale. Body mass index (BMI, $\mathrm{kg} / \mathrm{m}^{2}$ ) was calculated.

Two blood samples were collected after 12 $\mathrm{h}$ of fasting. One sample was used to measure total serum cholesterol (TC), HDL cholesterol, triglycerides (TRI), and glucose concentrations using standard enzymatic methods (Roche Diagnostics, Basel, Switzerland) and an automated Hitachi spectrophotometer (Tokyo, Japan). LDL cholesterol was calculated by the Friedwald formula [TC - (TRI/5 + HDL)]. These analyses were performed on the same day of blood collection.

The second sample was frozen and sent to Porto Alegre for genotyping. Genomic DNA was isolated by standard procedures. The genotyping protocols for the seven polymorphisms investigated in this study have been described. These include APOA1 -75 $\mathrm{G}>\mathrm{A},+83 \mathrm{C}>\mathrm{T}(5), A P O C 3-482 \mathrm{C}>\mathrm{T},-455$ $\mathrm{T}>\mathrm{C}$ and $3238 \mathrm{C}>\mathrm{G}(6,7)$, and $A P O A 4$ 
Q360H and T347S (11).

Allele frequencies were estimated by gene counting. Allele distribution and HardyWeinberg equilibrium were tested by $\chi^{2}$ tests. Haplotypes were derived using the Multiple Locus Haplotype Analysis program (12). Linkage disequilibrium between the sites was estimated using the Arlequin version 2.000 software (13). All continuous variables, except triglycerides, were normally distributed. All lipid values were analyzed separately by gender, and adjusted for age and BMI by linear regression analyses. Differences in mean lipid levels between genotypes were compared by the Student $t$-test, one-way ANOVA or KruskalWallis non-parametric test. Statistical analyses were performed using the SPSS 8.0 statistical package.

The distribution of genotype and allele frequencies for the seven polymorphic sites is shown in Table 1 . The observed genotype frequency distributions did not show statistically significant differences compared to those expected under Hardy-Weinberg equilibrium.

The frequency of the A allele of the -75 $\mathrm{G}>\mathrm{A}$ polymorphism in this sample (18\%) was within the same range as those reported for European or European-derived populations $(11-22 \%)(5,14)$. This frequency was somewhat lower in Africans (10\%) (9). The distribution of the $+83 \mathrm{C}>\mathrm{T}$ variant has been much less investigated than the -75 site. Thus far, the frequency of the less common allele has been reported to be about $4 \%$ in European or European-derived populations (5). However, the frequency of this allele was 10-fold higher (40\%) in an African population (9). As expected for an admixed sample, this frequency was intermediate (11\%) between Africans and Europeans. It should be pointed out, however, that Amerindians have not been tested for these markers. Strong linkage disequilibrium between the two APOAl sites was detected $\left(\mathrm{D}^{\prime}=\right.$ 1.00, $\left.\chi^{2}=22.6, \mathrm{P}=0.00001\right)$. The most common haplotype was -75G/+83C (71\%).

A high degree of ethnic variation has been described for the APOC $3-455 \mathrm{~T}>\mathrm{C},-482$ $\mathrm{C}>\mathrm{T}$, and $3238 \mathrm{C}>\mathrm{G}$ polymorphisms $(15,16)$. The less common allele frequencies observed in the present study (Table 1) were similar to those reported for Hispanic children (15) which are higher than those described for Europeans $(7,15)$. Due to strong linkage disequilibrium, four haplotypes $(-482 \mathrm{C} /$ $-455 \mathrm{~T} / 3238 \mathrm{C}$; $-482 \mathrm{~T} /-455 \mathrm{C} / 3238 \mathrm{C} ; 482 \mathrm{~T} /$ $-455 \mathrm{C} / 3238 \mathrm{G} ; 482 \mathrm{C} /-455 \mathrm{C} / 3238 \mathrm{C})$ accounted for $97 \%$ of the variability related to these APOC 3 polymorphisms.

As observed in other populations, the APOA4 360Q/Q genotype was the most frequent $(94 \%)$. The $360 \mathrm{H}$ allele frequency (3\%) observed in this admixed sample (Table 1 ) is very similar to that observed in African-

Table 1. Allele and genotype frequencies of the APOA1, APOC3 and APOA4 gene polymorphisms in children from a mixed Brazilian Northeastern population.

\begin{tabular}{|c|c|c|c|}
\hline & \multicolumn{2}{|c|}{ Genotype } & \multirow[t]{2}{*}{ Allele } \\
\hline & $\mathrm{N}$ & $\%$ & \\
\hline \multicolumn{4}{|l|}{$A P O A 1$} \\
\hline$-75 \mathrm{G}>\mathrm{A}$ & & & A (18.1\%) \\
\hline G/G & 277 & 66.9 & \\
\hline $\mathrm{G} / \mathrm{A}$ & 124 & 30.0 & \\
\hline $\mathrm{A} / \mathrm{A}$ & 13 & 3.1 & \\
\hline$+83 \mathrm{C}>\mathrm{T}$ & & & $\mathrm{T}(11.1 \%)$ \\
\hline $\mathrm{C} / \mathrm{C}$ & 329 & 79.5 & \\
\hline $\mathrm{C} / \mathrm{T}$ & 78 & 18.8 & \\
\hline$T / T$ & 7 & 1.7 & \\
\hline \multicolumn{4}{|l|}{ АРОCЗ } \\
\hline$-482 \quad C>T$ & & & $\mathrm{~T}(42.3 \%)$ \\
\hline $\mathrm{C} / \mathrm{C}$ & 145 & 35.0 & \\
\hline $\mathrm{C} / \mathrm{T}$ & 188 & 45.4 & \\
\hline$T / T$ & 81 & 19.6 & \\
\hline$-455 \quad T>C$ & & & C (46.9\%) \\
\hline $\mathrm{T} / \mathrm{T}$ & 127 & 30.7 & \\
\hline $\mathrm{T} / \mathrm{C}$ & 185 & 44.7 & \\
\hline $\mathrm{C} / \mathrm{C}$ & 102 & 24.6 & \\
\hline $3238 C>G$ & & & S2 (13.8\%) \\
\hline $\mathrm{C} / \mathrm{C}$ & 312 & 75.4 & \\
\hline $\mathrm{C} / \mathrm{G}$ & 90 & 21.7 & \\
\hline $\mathrm{G} / \mathrm{G}$ & 12 & 2.9 & \\
\hline \multicolumn{4}{|l|}{ APOA4 } \\
\hline $\mathrm{O} 360 \mathrm{H}$ & & & $H(2.8 \%)$ \\
\hline $\mathrm{Q} / \mathrm{Q}$ & 391 & 94.4 & \\
\hline $\mathrm{Q} / \mathrm{H}$ & 23 & 5.6 & \\
\hline T347S & & & S (14.1\%) \\
\hline $\mathrm{T} / \mathrm{T}$ & 309 & 74.6 & \\
\hline $\mathrm{T} / \mathrm{S}$ & 94 & 22.6 & \\
\hline $\mathrm{S} / \mathrm{S}$ & 11 & 2.8 & \\
\hline
\end{tabular}


Americans (17). This allele is found almost exclusively in European or European-derived populations and its presence in non-Caucasian populations has been proposed as a marker of European admixture (17). The $347 \mathrm{~S}$ allele, which displays a much wider distribution worldwide, was detected in about $14 \%$ of the subjects investigated (Table 1). This frequency is similar to that observed in US Hispanics (13\%), and somewhat lower than that described for Afro-Americans (8). Linkage disequilibrium was observed between the two polymorphisms $\left(\chi^{2}=8.82 ; \mathrm{P}\right.$ $\left.=0.003 ; \mathrm{D}^{\prime}=0.986, \mathrm{P}<0.00001\right)$. Three haplotypes were found: 360Q-347T, 360Q$347 \mathrm{~S}$, and $360 \mathrm{H}-347 \mathrm{~T}$ with frequencies of $84.5,12.7$, and $2.8 \%$, respectively.

As lipid differences between genders are well known to exist in children and adolescents (18), all association analyses were performed separately for boys and girls. Data on lipid variables according to gender and genotypes are presented in Table 2. No significant associations were observed between serum lipids and the two polymorphisms in the APOAl gene. The APOC $3 /$ -455 variant showed a significant effect on HDL cholesterol in girls $(\mathrm{P}=0.033)$; the $-455 \mathrm{C}$ carriers had higher HDL cholesterol than the TT genotype. Significantly higher plasma total $(\mathrm{P}=0.003)$ and LDL cholesterol $(\mathrm{P}=0.004)$ levels were observed in boys who were carriers of the $G$ allele at the APOC $3 / 3238 \mathrm{C}>\mathrm{G}$. Girls with the APOA4/ $347 \mathrm{~S}$ allele had significantly higher HDL cholesterol levels than girls with the other genotypes $(\mathrm{P}=0.016)$. The other polymorphic sites investigated were not associated with lipid levels in this sample. All of these associations were no longer statistically significant at the haplotype level (data not shown).

$\mathrm{Xu}$ et al. (14) reported an association between the APOA1 -75 polymorphism and plasma levels of total cholesterol, LDL cholesterol, apoB and apoA-I in Italian boys. Individuals with the $\mathrm{A}$ allele had higher mean levels of these lipid traits. Wang et al. (5) did not detect an effect for this APOAl polymorphism, but observed an influence of the +83 site variant on HDL cholesterol levels in Australian children of European descent. The absence of association of the two APOAI polymorphisms with lipid levels in Brazilian children observed in the present study is consistent with the findings of Kamboh et al. (9) in Africans. Since the estimated contribution of African genes (44\%) to this population is high (10), it is possible that the genetic background of the population studied might modulate the effect of $A P O A 1$ on lipid levels.

The effect of the APOC 3 polymorphisms on plasma lipids was modest in the children and neither polymorphism was associated with triglyceride levels, the most common finding in several studies with adults $(6,7)$. Since no significant associations were observed at the haplotype level, the genotype results should be viewed with caution, in view of the number of tests performed and the moderate sample size. No statistically significant differences in the distribution of -455 and -482 alleles in relation to lipids were reported in Italian (19) or Hispanic children (15). However, Shoulders et al. (19) described a modest effect of the $G$ allele at the $3238 \mathrm{C}>\mathrm{G}$ site on triglyceride levels in Italian schoolchildren. An increased frequency of the $-455 \mathrm{C}$ allele associated with elevated triglyceride and reduced HDL cholesterol levels was also reported in a young group of native Canadians (16).

No significant influence of the $360 \mathrm{H}$ allele on lipid levels or BMI was observed in the present young admixed Brazilian sample. However, the number of carriers of the $\mathrm{H}$ allele at the Q360H locus was too small to detect small differences in lipid levels in this sample. Mean HDL cholesterol values were significantly higher in girls, who were carriers of at least one $347 \mathrm{~S}$ allele, but this association was no longer significant at the haplotype level (data not shown).

Although we adjusted all lipid levels for 
Table 2. Association of APOA1, APOC3 and APOA4 genotypes and lipid levels in Brazilian children.

\begin{tabular}{|c|c|c|c|c|c|}
\hline & $N$ & TC (mg/dl) & LDL-C (mg/dl) & HDL-C (mg/dl) & $\mathrm{TG}^{+}(\mathrm{mg} / \mathrm{dl})$ \\
\hline \multicolumn{6}{|c|}{ APOA $1-75 \mathrm{G}>\mathrm{A}$} \\
\hline \multicolumn{6}{|c|}{ Boys } \\
\hline $\mathrm{G} / \mathrm{G}$ & 156 & $153.31 \pm 25.36$ & $93.60 \pm 21.88$ & $43.50 \pm 8.89$ & $81.46 \pm 36.69$ \\
\hline A Carriers & 65 & $156.26 \pm 23.56$ & $95.67 \pm 20.37$ & $44.86 \pm 9.11$ & $77.68 \pm 23.80$ \\
\hline P & & 0.424 & 0.513 & 0.303 & 0.802 \\
\hline \multicolumn{6}{|l|}{ Girls } \\
\hline G/G & 121 & $159.17 \pm 26.46$ & $96.35 \pm 23.38$ & $45.70 \pm 10.17$ & $85.61 \pm 31.58$ \\
\hline A Carriers & 72 & $160.81 \pm 30.40$ & $98.78 \pm 26.66$ & $43.75 \pm 8.74$ & $91.35 \pm 47.28$ \\
\hline & & 0.693 & 0.508 & 0.177 & 0.906 \\
\hline \multicolumn{6}{|c|}{$A P O A 1+83 C>T$} \\
\hline \multicolumn{6}{|c|}{ Boys } \\
\hline $\mathrm{C} / \mathrm{C}$ & 168 & $153.53 \pm 24.33$ & $93.49 \pm 20.58$ & $43.88 \pm 9.09$ & $80.55 \pm 35.04$ \\
\hline $\mathrm{T}$ Carriers & 53 & $156.24 \pm 26.47$ & $96.51 \pm 23.96$ & $43.97 \pm 8.60$ & $79.72 \pm 27.90$ \\
\hline P & & 0.490 & 0.372 & 0.950 & 0.928 \\
\hline \multicolumn{6}{|l|}{ Girls } \\
\hline $\mathrm{C} / \mathrm{C}$ & 161 & $159.86 \pm 27.67$ & $97.92 \pm 24.49$ & $44.45 \pm 9.51$ & $87.70 \pm 39.53$ \\
\hline $\mathrm{T}$ Carriers & 32 & $159.40 \pm 29.62$ & $93.89 \pm 25.37$ & $47.60 \pm 10.24$ & $88.03 \pm 31.07$ \\
\hline $\mathrm{P}$ & & 0.933 & 0.398 & 0.093 & 0.699 \\
\hline \multirow{2}{*}{\multicolumn{6}{|c|}{ APOC3 $-482 \quad C>T$}} \\
\hline & & & & & \\
\hline $\mathrm{C} / \mathrm{C}$ & 77 & $152.53 \pm 24.55$ & $92.70 \pm 21.42$ & $43.76 \pm 8.71$ & $80.60 \pm 33.06$ \\
\hline T Carriers & 144 & $155.06 \pm 25.02$ & $95.02 \pm 21.45$ & $43.98 \pm 9.12$ & $80.22 \pm 33.71$ \\
\hline $\mathrm{P}$ & & 0.470 & 0.444 & 0.862 & 0.954 \\
\hline \multicolumn{6}{|l|}{ Girls } \\
\hline $\mathrm{C} / \mathrm{C}$ & 68 & $156.12 \pm 26.97$ & $95.66 \pm 22.59$ & $43.22 \pm 9.35$ & $85.07 \pm 38.32$ \\
\hline $\mathrm{T}$ Carriers & 125 & $161.77 \pm 28.34$ & $98.12 \pm 25.69$ & $45.92 \pm 9.76$ & $89.21 \pm 38.18$ \\
\hline$P$ & & 0.180 & 0.507 & 0.064 & 0.656 \\
\hline \multicolumn{6}{|c|}{ APOC $3-455$ T>C } \\
\hline \multicolumn{6}{|c|}{ Boys } \\
\hline $\mathrm{T} / \mathrm{T}$ & 64 & $151.17 \pm 23.06$ & $91.40 \pm 19.87$ & $43.94 \pm 8.72$ & $80.11 \pm 34.98$ \\
\hline C Carriers & 157 & $155.40 \pm 25.48$ & $35.36 \pm 21.98$ & $43.88 \pm 9.08$ & $80.45 \pm 32.87$ \\
\hline & & 0.252 & 0.214 & 0.964 & 0.713 \\
\hline \multicolumn{6}{|l|}{ Girls } \\
\hline $\mathrm{T} / \mathrm{T}$ & 63 & $155.76 \pm 26.68$ & $95.49 \pm 21.69$ & $42.84 \pm 9.02$ & $85.81 \pm 39.60$ \\
\hline C Carriers & 130 & $161.73 \pm 28.41$ & $98.11 \pm 25.95$ & $46.00 \pm 9.85$ & $88.69 \pm 37.60$ \\
\hline & & 0.164 & $0.957^{++}$ & 0.033 & 0.789 \\
\hline \multicolumn{6}{|c|}{ APOC3 3238 C>G } \\
\hline \multicolumn{6}{|c|}{ Boys } \\
\hline $\mathrm{C} / \mathrm{C}$ & 168 & $151.45 \pm 23.39$ & $91.77 \pm 20.34$ & $43.89 \pm 8.48$ & $78.99 \pm 32.62$ \\
\hline G Carriers & 53 & $162.85 \pm 27.38$ & $101.95 \pm 23.08$ & $43.92 \pm 10.41$ & $84.64 \pm 35.78$ \\
\hline P & & 0.003 & 0.002 & 0.981 & 0.251 \\
\hline Girls & & & & & \\
\hline $\mathrm{C} / \mathrm{C}$ & 144 & $159.72 \pm 28.30$ & $96.85 \pm 24.45$ & $44.98 \pm 9.76$ & $88.76 \pm 38.65$ \\
\hline G Carriers & 49 & $160.55 \pm 27.07$ & $98.43 \pm 25.32$ & $44.94 \pm 9.53$ & $84.80 \pm 37.01$ \\
\hline P & & 0.824 & 0.699 & 0.981 & 0.672 \\
\hline APOA4 T347S & & & & & \\
\hline Boys & & & & & \\
\hline $\mathrm{T} / \mathrm{T}$ & 163 & $155.43 \pm 25.93$ & $95.20 \pm 22.58$ & $43.84 \pm 8.83$ & $82.39 \pm 35.27$ \\
\hline S Carriers & 58 & $150.67 \pm 21.25$ & $91.43 \pm 17.65$ & $44.08 \pm 9.37$ & $74.62 \pm 26.99$ \\
\hline & & 0.210 & 0.250 & 0.860 & 0.222 \\
\hline Girls & & & & & \\
\hline $\mathrm{T} / \mathrm{T}$ & 146 & $158.50 \pm 28.50$ & $96.77 \pm 25.02$ & $44.02 \pm 9.12$ & $88.12 \pm 39.55$ \\
\hline S Carriers & 47 & $163.76 \pm 25.95$ & $98.77 \pm 23.50$ & $47.91 \pm 10.82$ & $86.62 \pm 33.98$ \\
\hline $\mathrm{P}$ & & 0.263 & 0.628 & 0.016 & 0.762 \\
\hline APOA4 $\mathrm{Q} 360 \mathrm{H}$ & & & & & \\
\hline Boys & & & & & \\
\hline $\mathrm{Q} / \mathrm{O}$ & 209 & $154.51 \pm 25.18$ & $94.51 \pm 21.62$ & $43.90 \pm 8.98$ & $80.44 \pm 33.67$ \\
\hline $\mathrm{Q} / \mathrm{H}$ & 12 & $148.48 \pm 17.33$ & $88.99 \pm 17.43$ & $43.80 \pm 8.86$ & $78.75 \pm 29.75$ \\
\hline P & & 0.415 & 0.386 & 0.970 & 0.815 \\
\hline Girls & & & & & \\
\hline $\mathrm{Q} / \mathrm{Q}$ & 182 & $159.98 \pm 27.86$ & $97.71 \pm 24.87$ & $44.91 \pm 9.48$ & $86.68 \pm 36.44$ \\
\hline $\mathrm{Q} / \mathrm{H}$ & 11 & $156.44 \pm 30.26$ & $89.71 \pm 19.14$ & $46.03 \pm 13.11$ & $105.45 \pm 59.95$ \\
\hline$P$ & & 0.684 & 0.296 & 0.708 & $0.389^{++}$ \\
\hline
\end{tabular}

Data are reported as means \pm SD. Statistical analysis performed with ANOVA or ++Kruskal-Wallis test. +Unadjusted means, but test performed on log-transformed values. 
age and BMI, we did not ascertain the children's Tanner stage (which measures pubertal status); therefore, we cannot exclude an allelic effect of interaction between sexual maturity and lipid levels. However, it has been shown (20) that BMI closely correlates with the Tanner scale classification of the subjects, minimizing any interference by puberty with lipoprotein levels. Mean BMI was $17.52 \pm 3.34$ and $17.76 \pm 3.40$ in boys and girls, respectively. No association between $A P O A 1 / C 3 / A 4$ gene cluster polymorphisms and BMI was detected in this sample (data not shown). Therefore, if some effect of pubertal status on the associations observed was present, it should have been small.

In this highly heterogeneous population, all comparisons were performed among genotypes that are more robust for the effects of population stratification than in case-control studies. The children studied here have been exposed to much fewer environmental factors than adults, providing fewer opportuni- ties for interactions between these polymorphisms and the environment. As pointed out by Sing et al. (21), the effects of few genes will be invariant across populations and environmental strata; most will be context-dependent, as defined by gender, age, and other measures of exposure to environmental factors both internal and external to the individual. Therefore, if the contribution of these polymorphisms to the modulation of lipid levels depends on these exposures, the overall absence of associations with lipids in children was not an unexpected finding. The observed associations could also be spurious due to multiple statistical comparisons. Although the possibility of type II error could not be excluded, this study may be considered preliminary and suggests candidate genes for future association studies in this population. Therefore, before reaching definitive conclusions, the results of this study need to be confirmed in larger samples from the study population.

\section{References}

1. Karathanasis SK (1985). Apolipoprotein multigene family: tandem organization of human apolipoprotein Al, CIII, and AIV genes. Proceedings of the National Academy of Sciences, USA, 82: 63746378.

2. Fielding CJ \& Fielding PE (1995). Molecular physiology of reverse cholesterol transport. Journal of Lipid Research, 36: 211-228.

3. Jong MC, Hofker MH \& Havekes LM (1999). Role of ApoCs in lipoprotein metabolism: functional differences between ApoC1, ApoC2, and ApoC3. Arteriosclerosis, Thrombosis, and Vascular Biology, 19: 472-484.

4. Weinberg RB (2002). Apolipoprotein A-IV polymorphisms and diet-gene interactions. Current Opinion in Lipidology, 13: 125-134.

5. Wang XL, Badenhop R, Humphrey KE \& Wilcken DE (1996). New $\mathrm{Mspl}$ polymorphism at $+83 \mathrm{bp}$ of the human apolipoprotein $\mathrm{Al}$ gene: association with increased circulating high density lipoprotein cholesterol levels. Genetic Epidemiology, 13: 1-10.

6. Hegele RA, Connelly PW, Hanley AJ, Sun F, Harris SB \& Zinman B (1997). Common genomic variation in the APOC3 promoter associated with variation in plasma lipoproteins. Arteriosclerosis, Thrombosis, and Vascular Biology, 17: 2753-2758.

7. Oppert JM, Fumeron F, Moreel JF \& Apfelbaum M (1992). Association of a DNA polymorphism of the apolipoprotein A-I/C-III/A-IV gene cluster with hypertriglyceridemia in obese people. International Journal of Obesity, 16: 891-896.
8. Wang GQ, DiPietro M, Roeder K, Heng CK, Bunker CH, Hamman RF \& Kamboh MI (2003). Cladistic analysis of human apolipoprotein A4 polymorphisms in relation to quantitative plasma lipid risk factors of coronary heart disease. Annals of Human Genetics, 67: 107-124.

9. Kamboh MI, Bunker CH, Aston CE, Nestlerode CS, McAllister AE \& Ukoli FA (1999). Genetic association of five apolipoprotein polymorphisms with serum lipoprotein-lipid levels in African blacks. Genetic Epidemiology, 16: 205-222.

10. Salzano FM \& Bortolini MC (2002). The Evolution and Genetics of Latin American Populations. Cambridge University Press, Cambridge, UK.

11. Fiegenbaum M \& Hutz MH (2003). Further evidence for the association between obesity-related traits and the apolipoprotein A-IV gene. International Journal of Obesity, 27: 484-490.

12. Long JC (1999). Multiple Locus Haplotype Analysis, Version 2.0. Software and Documentation Distributed by the Author. Section on Population Genetics and Linkage. Laboratory of Neurogenetics, NIAAA, National Institutes of Health, Bethesda, MD, USA.

13. Schneider S, Roessli D \& Excoffier L (2000). Arlequin Version 2000. A Software for Population Genetics Data Analysis. University of Geneva, Geneva, Switzerland.

14. Xu C-F, Angelico F, Del Ben M \& Humphries SE (1993). Role of genetic variation at the Al-CIII-AIV gene cluster in determining 
plasma APO Al levels in boys and girls. Genetic Epidemiology, 10: 113-122.

15. Talmud PJ, Berglund L, Hawe EM, Waterworth DM, Isasi CR, Deckelbaum RE, Starc T, Ginsberg HN, Humphries SE \& Shea S (2001). Age-related effects of genetic variation on lipid levels: The Columbia University BioMarkers Study. Pediatrics (serial online) 108: http://www.pediatrics.org./cgi/content/full/108/3/e50. Accessed December 12, 2001.

16. Hegele RA, Connelly PW, Hanley JGA, Sun F, Harris SB, \& Zinman B (1997). Common genomic variants associated with variation in plasma lipoproteins in young aboriginal Canadians. Arteriosclerosis, Thrombosis, and Vascular Biology, 17: 1060-1066.

17. Kamboh MI \& Ferrell RE (1990). Genetic studies of human apolipoproteins. XV. An overview of IEF immunoblotting methods to screen apolipoprotein polymorphisms. Human Heredity, 40: 193207.
18. Brotons C, Ribera C, Perich RM, Abrodos D, Magaña P, Pablo S, Terradas D, Fernandez F \& Permanyer G (1998). Worldwide distribution of blood lipids and lipoproteins in childhood and adolescence: a review study. Atherosclerosis, 139: 1-9.

19. Shoulders CC, Grantham TT, North JD, Gaspardone A, Tomai F, Fazio A, Versaci F, Gioffre PA \& Cox NJ (1996). Hypertriglyceridemia and the apolipoprotein CIII gene locus: lack of association with the variant insulin response element in Italian school children. Human Genetics, 98: 557-566.

20. Aalto-Setälä K, Viikari J, Akerblom KK, Kuusela V \& Kontula K (1991). DNA polymorphisms of the apolipoproteinB and Al/CIII genes are associated with variations of serum low density lipoprotein cholesterol level in childhood. Journal of Lipid Research, 32: 1477-1487.

21. Sing CF, Stengard JH \& Kardia SLR (2003). Genes, environment, and cardiovascular disease. Arteriosclerosis, Thrombosis, and Vascular Biology, 23: 1190-1196. 